\title{
Research on The Ballistic Non-contact Start-end Device
}

\author{
Yunfeng Liura ${ }^{1, a}$ Xiaoli Zhao ${ }^{1}$ and Xiaodong Zhou ${ }^{1}$ \\ ${ }^{1}$ Mechanical Engineering College, Shijiazhuang, 050003, China \\ a5977150@qq.com
}

Keywords: ballistic, start-end, non-contact, target, velocity

\begin{abstract}
The method which adopts start-end device to measure the velocity is in com- mon a method of measuring the velocity. The characteristics of this method is in brief the equipments need, operation convenience, test result credibility, measuring the error margin small. It not only can measure the velocity of the normal ammunition, but also can measure the velocity of special ammunition. The trajectory passed the bullet to equip a ballistic segment of marking X1, 2 with the area. The instrument measures the time t1, 2 that a bullet experience when passing two targets. Using to measure $v=X_{1,2} / t_{1,2}$, compute average speed for a bullet to pass two targets with the formula, and is the moment speed that the bullet passes two targets middles it.

\section{Introduction}

Start-end device is a kind of special made feeling machine and it can constitute a piece noodles in the space. Using target constitute of the space flat surface needs the flight direction of perpendicularity and bullet and be bullet to cut through that noodles. It can output a signal in time, conduct and actions account hour signal of instrument start or stop. When the area cut to equip to press its work bullet whether is divided into contact type with its contact to equip and not the contact type area cut to equip 2 kinds and this text aims at non-contact start-end device to carry on a research.
\end{abstract}

\section{Coil Target}

Coil target is make use of the electromagnetic induction principle make into of 1 kind noncontact start-end device. Based on the work principle, it can is divided into the excitation coil target with induction respond coil target.

Excitation coil target. The excitation coil target rounds two coils in its target the frame, one is called the coil of excitation and work the top direct current excitation magnetoelectricity flow. The excitation magnetoelectricity flow can on-line turn target surroundings creation stable constant magnetic field, another coil is called respond coil and be bullet to pass the excitation coil target, because the function of bullet make its top creation respond electricity power, this electricity power enlarge after starting or closing account hour instrument of signal.

While flowing in the last top direct current excitation magnetoelectricity of the coil of excitation when the excitation coil target work, making coil target surroundings to produce stable magnetic field, being bullet make into by iron magnetism material to pass coil, the $\mathrm{Ci}$ flux in the coil will take place variety, should change to be been placed in magnetic field in of respond coil to feel.

The excitation respond signal can look like:

$$
e=-n v \frac{d \varphi}{d t}=\frac{3}{2} \pi \mu \operatorname{Ivnn}_{1} R_{b}^{2} r_{1}^{2} x\left(r_{1}^{2}+x^{2}\right)^{-\frac{5}{2}}
$$

We can see from the type, under the coil target certain condition that is measured bullet material must, bullet airspeed, use, respond coil up creation of respond signal of the size only relates to the bullet quality heart distance near the coil and be its opposite position as $r_{1 / 2}$, respond coil output's to respond signal to contain top value. 
We can also see from the type, if the bullet is along the stalk line of coil target pass and then respond coil to up acquire of respond signal in addition to changing with the opposite position, would also with the bullet distance near the target turn variety but change.

Induction respond coil target. Induction respond coil target to round to have inside frame a have the certain full circle count of coil. Induction respond coil target in order to promise its work credibility, has to use bullet magnetize an instrument to magnetize bullet before measuring soon, bullet after magnetize an equal to respond accidentally and very soon. It passes coil target, respond coil to incise line of magnetic force, above it respond a similar respond of sine wave signal, its expression type can write for:

$$
e=\frac{3}{2} \mu_{0} m_{c} n v r^{2} x\left(r^{2}+x^{2}\right)^{-\frac{5}{2}}
$$

Give the signal formula of the respond of being able to see from two kinds of coil target, when two kinds of coil targets measure soon, acquire of respond a signal form is same. Make de/dx=0, $x=$ $\pm r / 2: 00$, respond the signal can get a Feng value.

The open space target is to make use of the sun light in the atmosphere of spread to cast light to do light source(use light source of need the specially made indoors), according to light electricity conversion the principle make into of a kind of area cut device.

The open space target presses to use a way and can is divided into 2 kinds: target and angle of elevation open space of the level open space target. The level open space target generally useds for level or close level to shoot of low stretch the diagraph of ballistic bullet speed, at measure soon accuracy is not that high can also use to bullet speed of measure the angle of fire .Level open space target is a sow in an usage under the open country condition of the area cut device. If used for it indoor to measure soon, then need to be install up the artificial light source. To the request of the artificial light source of allocation be the light strength of light source is very stable and otherwise trigger a creation mistake.

The angle of elevation open space target is actually a bullet to measure system, this kind of measures system in addition to measuring the bullet speed that the small angle of fire shoot, can also measure the bullet speed of angle of fire blast-off. The usage adaptability ratio level open space target of angle of elevation open space target ising strong have to be many, but the price be higher and make it be subjected to restriction in the usage of each one ballistic station.

\section{On-Off Target}

Net target. Breaks target is contact type the area cut device, it from insulate material to make into a frame, press the certain to be apart from in the frame or so both sides, establish two lines of lines pillar, round metals silk on the round of frame line pillar before shoot. It two carry a point can with instrument of the importation back track connect.

A rightness of nets target is impossibly completely consistent while create, in the meantime, bullet while flying more target noodles, the opposite position which touches shot target noodles also not same, in addition return because of two electricity parameters of importation electric circuits of target also can't completely symmetry, make to input of trigger pulse to in response to of the target be apart from, with physically place two distances of target not and mutually consistently, be apart from creation target an error margin.

The advantage of net target is that the structure is simple and the work is dependable. But a net target can use once, again use need to re- connect target line or repair target paper, work bump shot with bullet, have certain influence to bullet sport, measure soon bullet can't assemble a true detonator.

Foil target. Foil target is made of 1 tier of insulate carton, both sides each glue to stick an aluminum screen and the aluminum foil derivation line. Before shooting, two derivation lines and instrument electric circuit conjunctions, two aluminum screens become two electrodes. When the 
bullet crosses the target, it makes into the metls material because of bullet, will make two aluminum screens in a twinkling lead, will produce negative the Tu jump pulse, this negative the jump pulse of ex- follow, the foil target output target ignal.

A foil target can use many times, work credibility, the consistency is also better. The foil target is also a contact start-end device. Though choosing to use a very thin metals foil with insulating a layer, it still produces influences to the sport of the bullet and can't use true detonator bullet to measure. Forever have already make as well while in addition being bullet to pass metals screen and insulate a layer to be subjected to dint and pull to stretch with break process, will also have certain target to be apart from an error margin. The foil target also exists importation electric circuit the problem of the dissymmetry, but because it is a small electric resistance to turn on electricity the process. Its influence can neglect.

\section{Photoelectric Target}

This is to particularly point to make use of artificial light source and a kind of area which applies the light electricity conversion principle cuts device. It of basic work principle and open space target be similar and all made use of bullet to once fly target noodles, change being measure by light of photoelectric cell but produce telecommunication number. But the open space target act noodles be a photoelectric cell visual field, but light electricity the act noodles of the target be the light act that the artificial ray which projects light upon photoelectric cell constitute.

According to the photoelectric cell use of how much be divided into a list tube type with much $t$ tube type be 2 kinds. List tube the type light act light electricity target, from order light source, two pillar noodles lens or tailor growth of flat surfaces lenses and a photoelectric cell constitute. The light source is generally the light of $\mathrm{Lu} \mathrm{Wu}$. A lens remits light source parallel light light act, another lens focuses a parallel light light act on the photoelectric cell and constitute 1 to have thus must the act noodles size and act be thick of parallelism light light act. When the bullet once flew light act, covered parts of rays, make the be subjected to of photoelectric cell light quantity the occurrence change but produce telecommunication number.

Much tube type light act light electricity target uses a lens. This lens orders the light source to the $\mathrm{Wu}$ light to remit into parallelism light, the composing parallelism light light act, project light upon in lining up into the photoelectric cell of one row. The alignment density of photoelectric cell, the basis is the diagraph need of the least play path. All photoelectric cells merge to carry at the importation of enlarge the orthopedics electric circuit. When the bullet once flew a light act, be subjected to of at least a photoelectric cell light is all cover. So, the photoelectric cell be subjected to light quantity variety big, work more dependable. Act noodles size which much takes care of a light act light an electricity target is muchdecided by anastigmatic size, but has nothing to do with the opposite and intelligent degree of the photoelectric cell, so the act noodles can do more and greatly. Generally and all make into the act $0.5-1 \mathrm{~ms}$, the act breadth $1 \mathrm{~m}$, act thick and less than 4-5 mms and large light electricity target. It uses for the bullet speed which measures bigger caliber, or the small arms leave the gun muzzle farther bullet speed. If go together with to handle device by the equal electronics circuit and the data, it canned also use to measured bullet to once fly target of sit a mark.

The light gives or gets an electric shock target of the act noodles be relatively the light act that the ray constitute, keep a view, this to the exaltation install accuracy's overcoming target be beneficial apart from the error margin. The target often made in to fix the frame type that the target be apart from structure, installed is higher apart from the accuracy. Usually the target way uses indoors. But it of the anti-vibration can be worse and be subjected to the big vibration will result in the light source tremble to move and thus cause a mistake to trigger.

\section{References}

[1] Xia Ji,Wenlong Sha:Journal of Projectiles ,Rockets,Missiles and Guidance,Vol. 24(2004) No. 5, p.542-544. (In Chinese) 
[2] Li Wang:Journal of Ballistics, Vol. 13(2001) No 5,p.79-83. (In Chinese)

[3] Ling Ma,Zhengyu Cai,Fenglei Cheng,Hong Zhu: Journal of Ballistics,Vol 15(2003) No. 4,p.87-91. (In Chinese)

[4] Yushu Zhao,Dongyao Zhao,Hui Zhao: Journal of Projectiles ,Rockets,Missiles and Guidance,Vol.28(2008) no.4,p.285-287. (In Chinese)

[5] Jing Wu,Tieling Wang,Song Wang:China Measurement Test,Vol.35(2009) No.1, p.114-117. (In Chinese) 